\title{
Correction to "Metabolic Disposition of Luteolin Is Mediated by the Interplay of UDP-Glucuronosyltransferases and Catechol-O-Methyltransferases in Rats"
}

\author{
In the above article [Wang L, Chen Q, Zhu L, Li Q, Zeng X, Lu L, Hu M, Wang X and Liu Z (2017) Drug Metab \\ Dispos 45:306-315; DOI: https://doi.org/10.1124/dmd.116.073619], information regarding the co-corresponding \\ author was omitted. \\ The following co-corresponding information should have been included:
}

Co-corresponding author: Prof. Xinchun Wang, The First Affiliated Hospital of the Medical College, Shihezi University, Shihezi, Xinjiang, 832008, PR China. Tel: +86993-2855827; E-mail: cwjwxc@163.com.

All versions of the article are replaced with the issuance of this erratum.

The compositor apologizes for any inconvenience. 